\title{
CONHECIMENTO E USO DE MÉTRICAS DE MARKETING
}

\author{
KNOWLEDGE AND USE OF MARKETING METRICS \\ DOI: http://dx.doi.org/10.12712/rpca.v5i1.19
}

\author{
Fabricio Palermo Pupo \\ Universidade Positivo - Curitiba - PR

\section{Delane Botelho} \\ Escola de Administração de Empresas de São Paulo - FGV-SP
}

\section{RESUMO}

A sociedade evoluiu, a oferta à educação superior aumentou e as instituições de ensino superior (IES) privadas passaram a investir mais em ações de marketing. A partir de 1997 houve mudanças relevantes na gestão deste segmento. 0 objetivo desta pesquisa é identificar na literatura métricas de marketing e o nível de conhecimento e uso de métricas pelos gestores de IES. A metodologia utilizada neste estudo de natureza exploratória foi a pesquisa qualitativa por meio de entrevista em profundidade, realizada com oito dirigentes de marketing de IES privadas, da cidade de Curitiba - PR. Concluiu-se que o conhecimento empírico existe, mas se fazem necessários o uso de métodos e técnicas. E verificou-se que essas ações começaram a ser praticadas nos últimos cinco anos pela maioria das instituições pesquisadas e a tendência é que exista maior desenvolvimento sobre o tema. Pesquisas futuras são discutidas à luz da teoria de marketing.

Palavras-chave: Métricas de marketing. Indicadores de desempenho. Instituições de ensino superior.

\begin{abstract}
Society has evolved, the offer higher education has increased and private institutions of higher education (IES) have invested in marketing. Since 1997 there has been relevant changes in the management of this segment. The objective of this research is to identify in the literature marketing metrics and level of knowledge and use of metrics by managers of IES. The methodology used in this study of an exploratory nature was a qualitative study through extensive interviews, done with eight marketing professionals of IES in the city of Curitiba, PR. It was concluded that empirical proof exists, but are necessary to use methods and techniques. And it was found that these actions began to be applied in the last five years by the majority of institutions researched and the tendency is that there exists further development on the subject. Future research is being discussed concerning marketing theory.
\end{abstract}

Keywords: Marketing metrics. Performance indicators. Private institutions of higher education. 


\section{INTRODUÇÃO}

O cenário do Ensino Superior no Brasil sofreu alterações a partir do final da década de 1990 em relação ao número de instituições. Em 1997, havia 689 Instituições de Ensino Superior (IES) privadas e 211 públicas. Entre 1997 e 2007 o número de instituições privadas aumentou em 256\%. A partir de 2001 o número de alunos matriculados no ensino médio apresentou-se constante (BRAGA et al., 2005), com isto

Em relação ao número de IES em funcionamento no ano 2008, houve uma redução de 29 instituições, comparativamente ao ano 2007, consolidando outra tendência do mercado, que é a estabilização na criação de novas IES. A explicação mais provável para esta diminuição de instituições são as fusões ou aquisições. No entanto, o Instituto Nacional de Estudos e Pesquisas Educacionais Anísio Teixeira INEP (2009a) mostrou que a redução de IES não seguiu a porcentagem equivalente ao número de vagas ofertadas, pois, em 1997 havia aproximadamente 700 mil vagas e em 2003, dois milhões. Os dados mostram também que em 2008 as vagas ofertadas foram de três milhões. A análise do número de IES com as vagas ofertadas somadas ao número de cursos ofertados amplia a visão do mercado, pois em 1997 havia 6.132 cursos e em 2008 cerca de 25 mil, incluindo presenciais e a distância segundo.

Contudo, os gestores de IES estão preocupados com o número de matrículas oriundas dos processos seletivos e a retenção dos alunos. Para isso são necessárias estratégias de marketing aplicadas ao setor, o qual não possui um histórico de ações e inovações em marketing. 0 tema desta pesquisa aborda a questão de mensurar estas ações e com isso poder controlá-las. Foi analisado nesta pesquisa que o número de vagas foi crescente até 2003 e dados do INEP (2009a) apontam para uma continuidade deste crescimento. Isto é um dos fatores que está fazendo as IES investirem em novas estratégias de comunicação e marketing (PORTO, 2003; BRAGA et al.,2005)

Em 2009 foram registradas 1,4 milhão de carteiras em cursos presenciais de Universidades, Centros Universitários e Faculdades desocupadas. Sabe-se que o número de novas vagas no Ensino Superior em 2008 foi de 2.985.137. Isto significa que a cada 100 vagas do ensino superior brasileiro, 49 ficam ociosas, e para as instituições particulares, sem a receita destas vagas, pode-se comprometer a sua saúde financeira (INEP, 2009b).

As considerações sobre o número de vagas ociosas nas IES e uma estabilidade na demanda (INEP, 2003), alertam as instituições para a competição por novos alunos matriculados e a retenção de alunos. Entretanto, há instituições mal preparadas para esta competição na captação de alunos e que podem perder espaço ou até deixar o mercado. É uma situação de sobrevivência e adaptação para o setor.

Os gestores das instituições educacionais reconhecem que há problemas de marketing, pois o declínio do número de alunos potenciais e de alunos matriculados são indicadores sobre a sua dependência em relação ao mercado que atendem. Com esta visão, as IES investem em melhorias, em diferenciais, na qualidade do ensino e profissionalização na gestão, bem como, mais atenção ao setor de marketing (KOTLER e FOX, 1994; PORTO, 2003; BRAGA et al., 2005;). De acordo com Facó (2006), muitas IES vêm aumentando a verba em comunicação e marketing (MÍDIA DADOS, 2005). Em 2003, mais de R\$ 400 milhões foram investidos pelas IES em mídia impressa, em 2007 o investimento foi de R\$ 625 milhões (MÍDIA DADOS, 2007). Este aumento do número de IES e a tendência de uma demanda menor que o número de vagas ofertadas (alunos provenientes do ensino médio) elevaram a importância de um tema no meio acadêmico e organizacional, que é a utilização de ferramentas de marketing no setor educacional. Não obstante a sua utilização, os gestores de marketing precisam conhecer e saber utilizar métodos de mensuração para avaliar o desempenho destas ferramentas (WEBSTER, 1981; HAUSER e KATZ, 1998; CLARK, 1999; AMBLER, 2000; AMBLER e KOKKINAKI, 2004; BARWISE, 2004; PATTERSON, 2007). O uso de métricas para explicar fenômenos é claro nas ciências exatas e biológicas, porém, nas ciências sociais aplicadas, isto é pouco transparente e há carência de métodos ou ferramentas disponíveis para gestão. Devido essa escassez de ferramentas e ausência de rigor na 

mensuração de ações de marketing surge o assunto desta pesquisa.

\section{PROBLEMA DE PESQUISA}

Com o aumento do número de IES, das vagas ofertadas de cursos superiores e uma demanda estável pelo ensino superior (INEP, 2009a), os gestores das IES preocupam-se em desenvolver novas estratégias e táticas de marketing para atrair mais alunos e com isso preencher o maior número das novas vagas ofertadas.

Segundo Hauser e Katz (1998) criar estratégias e dirigir uma campanha publicitária é mais simples que propor as métricas de desempenho. Mensurar estas ações é algo que passou a ser estudado com maior atenção a partir da década de 1980. No ensino superior privado, este pensamento de melhorias nas estratégias de marketing e suas mensurações foram observados inicialmente em 2003 com a reunião de 500 representantes de instituições de ensino no $1^{\circ}$ Congresso Brasileiro de Marketing e Comunicação para Instituições de Ensino, realizado pelo Sindicato das Entidades Mantenedoras de Ensino Superior no Estado de São Paulo (STRAUSS, 2003).

O objetivo desta pesquisa foi construído a fim de identificar o grau de conhecimento e uso das métricas de marketing nas instituições de ensino superior privadas. A questão que norteia a pesquisa é: Quais as métricas de marketing mais usadas e como são utilizadas em Instituições de Ensino Superior privadas?

\section{REFERENCIAL TEÓRICO}

As empresas crescem, evoluem, os produtos são melhorados e o consumidor passa a ter diversas marcas a sua frente para comparar e escolher. Um exemplo é visto ao entrar em um supermercado e observar a prateleira de certa categoria de produtos e perceber que existe uma grande oferta de marcas diferentes. As organizações enfrentam concorrentes e atendem a um consumidor com acesso à internet, a qual possibilita comparar produtos e marcas.

Devido a essa competição entre os concorrentes e maior acesso às informações pelos consumidores, há necessidade de rever as estratégias de marketing e comunicação que façam a marca de uma organização estar mais presente na vida das pessoas e com isso aumentar a chance de ser mais consumida.

Medir as ações de marketing tem sido um desafio para os executivos (FARRIS et al., 2007), pois as organizações precisam comprovar os resultados das estratégias e expor aos acionistas ou sócios. A fim de medir estas ações estratégicas com precisão, entender melhor os resultados e avaliar o desempenho dos executivos, a literatura de negócios insere um tema recorrente da disciplina de administração estratégica - as medidas de desempenho (VENKATRAMAN, 1986). É uma área em que muitos profissionais não possuem afinidade e tem sido uma exigência do mercado (FARRIS et al., 2007). O Quadro 1 apresenta um histórico com os autores que promoveram as primeiras publicações sobre avaliação de desempenho em marketing o qual, a partir da década de 1980, houve maior interesse por parte das organizações e universidades em entender profundamente $\mathrm{o}$ assunto (WEBSTER, 1981; Deshpandé, Farley e Webster, 1993). 
Quadro 1: Histórico de autores que pesquisaram métricas de marketing

\begin{aligned} & \hline Webster (1981) $\begin{array}{l}\text { Estudou sobre a ligação entre produtividade de marketing e os conceitos e } \\ \text { técnicas de seu gerenciamento. }\end{array} \\ &$\hline Parasuraman, Zeithaml e Berry $\begin{array}{l}\text { Propuseram métricas de qualidade em serviços sob o enfoque de como o } \\ \text { (1985) }\end{array} \\ &$\hline serviço foi entregue e qual era a expectativa do cliente. \end{aligned}

As medidas de desempenho surgiram dentro da linha de estudos em estratégias, mas outras subdivisões da administração, como finanças e marketing também as adotaram e fizeram suas observações particulares a respeito do conceito. Na administração mercadológica haviam autores que sinalizavam, também desde a década de 1980, sobre a necessidade de criar formas de mensuração do desempenho das ações de marketing e munir os gestores com informações precisas (WEBSTER, 1981; SRIVASTAVA et al., 1998).

Após estas iniciativas, passou-se à fase da evolução do conceito e identificação do seu uso nas organizações. Barwise e Farley (2004) realizaram um estudo sobre a mensuração das ações e despesas de marketing em indústrias de cinco países (Estados Unidos, Japão, Alemanha, Reino Unido e França) e identificaram que a maioria usa em média duas das seis métricas de marketing mais conhecidas. A métrica mais utilizada, participação de mercado (market share), está presente na gestão de $79 \%$ das empresas e, em seguida, a métrica qualidade percebida do produto/serviço é utilizada por $77 \%$ delas. Outras métricas, como o valor atual/potencial do tempo de vida do cliente são relatadas em apenas $40 \%$ das empresas.

Ainda na pesquisa de Barwise e Farley (2004) observaram que dentro dos países pesquisados existem diferenças culturais e de gestão entre eles, como as empresas alemãs que afirmam serem os maiores adeptos ao uso de métricas e as empresas japonesas em considerar que utilizam pouco, as métricas em seus negócios. Apesar das diferenças culturais, existem definições em comum a respeito das métricas, por exemplo, no estudo de Lovelock e Wright (2001), a qualidade percebida do produto/serviço refere-se a uma avaliação geral que uma pessoa faz a respeito de sua experiência com ele em certo momento.

Gerenciar orçamentos e conduzir estratégias de marketing sem saber qual a contribuição para o valor da marca de uma empresa pode sinalizar uma falha da gestão. 0 mercado de Marketing Direto faturou, no ano de 2007, R\$17,4 bilhões, o que representa um crescimento de 15,2\% em relação a 2006 (MELLO, 2008). Comparativamente, em 2000 o faturamento era de $R \$ 7,5$ bilhões. No setor educacional, Facó (2006) mostra que foram investidos em marketing valores superiores a 400 milhões de reais, porém não se encontram dados sobre o retorno sobre o investimento em marketing (ROIM). Segundo Webster (1981) apud Grinberg (2000):

“... o marketing tem sido, nos últimos anos, muito questionado, em relação à sua produtividade. Já no início da década de 1980, Webster (1981) mostrava, em estudo realizado com altos executivos de 21 grandes corporações americanas, que seus profissionais de marketing geralmente não pensavam de forma inovadora e empreendedora, atribuindo parte do problema aos sistemas utilizados para dirigir, avaliar e controlar a performance de suas atividades. Segundo o autor, aparentemente, havia pouca ou nenhuma ligação entre a análise da produtividade de marketing e conceitos e técnicas da ciência de gerenciamento desenvolvida nas duas últimas décadas." 
Medir a eficácia de uma produção industrial é algo tangível, controlável, no entanto, Parasuraman, Zeithaml e Berry (1985) enfatizam que a qualidade em produtos tangíveis é descrita e mensurada, e que qualidade em serviços é largamente indefinida e não pesquisada. Ainda, medir a qualidade em serviços significa entender como o serviço foi entregue e qual era a expectativa do cliente. Os métodos de se avaliar serviços são, até o momento, subjetivos ou ligados a um ou outro referencial. Venkatraman e Ramanujam (1986) pesquisaram sobre um esquema classificatório bidimensional que realça dez modos diferentes para mensuração de desempenho empresarial em pesquisa de estratégia. Com isso, é inserida na ciência administrativa uma nova visão de se mensurar atividades intangíveis, como os serviços.

No início da década de 1990 foram apresentados estudos sobre métodos de mensuração da orientação para o mercado, um assunto proveniente da administração estratégica e muito pesquisado por acadêmicos e praticantes na época (KOHLI, JAWORSKI e KUMAR, 1993). Outro estudo da mesma década buscou pesquisar em empresas japonesas, a questão de orientação para o cliente como forma de estratégia e inovação para o mercado e constataram que o desempenho empresarial é acrescido quando se investe em inovação (DESHPANDÉ, FARLEY e WEBSTER, 1993).

No final da década de 1990 a mensuração do desempenho nas empresas é conduzida por dois critérios: crescimento de vendas e rentabilidade do patrimônio. (MORAES, 1998). Outros autores também apresentaram estudos sobre métricas de marketing e o desempenho empresarial e compararam indicadores subjetivos (de percepção) e objetivos (retorno sobre ativos, taxa de crescimento de vendas e lucratividade). 0 estudo sugere que estes indicadores apresentaram positiva e significativa correlação com a performance geral das empresas, assinalando que esses três indicadores podem ser utilizados quando se pretende avaliar a performance empresarial de forma subjetiva (Perin e Sampaio, 1999).

Neste momento da história da evolução dos conceitos de métricas de marketing, uma pesquisa apresenta três temas que abordam a mudança de pensamento do uso de medidas simples de mensuração (outputs measures) para o uso de métricas amplas. Assim, foram propostas as seguintes idéias: a transição das medidas financeiras para as não financeiras, a expansão da mensuração de resultados de marketing para a mensuração das entradas de marketing (input measures) e a evolução da visão unidimensional de medidas de desempenho para a visão multidimensional (Clark,1999).

A partir do final da década de 1990 que os estudos das métricas de marketing começam a estar mais presentes nos trabalhos científicos apresentados em congressos e publicações de revistas científicas (ALMEIDA, 2007).

\section{O USO DO MARKETING E A APLICAÇÃO DAS MÉTRICAS NASIES}

Alguns gestores de IES apresentam rejeição ao uso do marketing para o ensino superior e isso afeta o aprimoramento e uso técnico-profissional das ferramentas de marketing para enfrentar a concorrência, o aumento na oferta de vagas e o pouco crescimento na demanda (Cobra e Braga, 2004). Porém, a partir do início de 2000, as IES passaram a reconhecer a necessidade e o valor de se adotar um planejamento de marketing (STRAUSS, 2003).

\section{PAINEL DE CONTROLE NA GESTÃO DAS MÉTRICAS DE MARKETING}

O controle de marketing é um sistema preventivo, abrangente, que envolve a análise do plano de uma forma geral, com a determinação de metas e o seu alcance. No momento que um plano de marketing é implantado pode ocorrer alterações no mercado. 0 sistema de controle de marketing inclui técnicas para avaliar se as metas do plano estão sendo atingidas e realizar ajustes quando isto não estiver ocorrendo. 0 controle estratégico consiste de uma avaliação sistemática do desempenho de marketing da instituição em relação a suas oportunidades de mercado (KOTLER e FOX,1994).

Esta avaliação sistemática do desempenho de marketing pode ser traduzida em um modelo concreto, o qual é chamado de painel de controle de marketing (dashboard). Uma vez que uma empresa define as 
métricas de marketing, pode criar um painel que irá fornecer uma maneira de controlar visualmente as suas métricas (PATTERSON, 2007; QUEIROZ, 2009).

\section{O CONCEITO E AS MÉTRICAS UTILIZADAS NO MARKETING}

Em relação ao conceito da gestão das métricas de marketing, Patterson (2007) define como a prática organizada no equilíbrio dos processos, sistemas e pessoas envolvidas para um conjunto comum de metas e objetivos.

Para Grinberg (2001), a teoria de métricas de marketing, originalmente, abrange cinco grandes linhas de pesquisas, as quais compõem um modelo em relação a gestão de métricas de marketing e engloba uma forma múltipla de se utilizar as avaliações. Os cinco grandes tópicos são: o valor do cliente, valor da marca, comércio eletrônico, mix de métricas em marketing e medidas financeiras. Farris et al. (2007) propõem que as métricas de marketing podem estar agrupadas de uma forma diferente da proposta por Grinberg (2001), e com isso é proposto oito grandes áreas para a gestão das métricas de marketing, que são: participação em corações, mentes e mercados; margens e lucros; gerenciamento de produtos e de portfólio; rentabilidade do cliente; gerenciamento da equipe de vendas e do canal; estratégia de preços; promoção; métricas da mídia e da web e marketing e finanças.

\section{O USO E A QUANTIDADE DE MÉTRICAS DE MARKETING NAGESTÃO}

A importância do uso das métricas de marketing pelas organizações se dá pelas análises e mensurações feitas a respeito de algo planejado, mas concentrar a estratégia de mensuração em métricas relevantes, relacionadas com os produtos ou serviços, é uma tarefa técnica que depende de habilidades (PATTERSON, 2007).

O uso preciso de métricas de marketing em uma organização serve de apoio nas tomadas de decisão (DAVIS, 2007). Nas IES, várias métricas podem ser usadas para medir o desempenho das ações de marketing, porém existe a questão da relevância das métricas para a gestão (HAUSER E KATZ, 1998).

Na proposta de Davis (2007) existem várias possibilidades de medir o desempenho do marketing nas IES, cabe ao gestor organizar e definir quais são as mais relevantes. Cobra e Braga (2004) afirmam que o marketing das IES precisa ser aprimorado e novas estratégias são necessárias, mas segundo Patterson (2007) não bastam apenas novas ações, tem que medi-las para saber se estão contribuindo para as metas da organização ou não.

Segundo Davis (2007) existem métricas comuns em marketing como vendas e preferência por uma marca, mas as organizações percebem a necessidade de combiná-las a outras métricas como a taxa de adoção de novos produtos e o valor da marca. Estes tipos de métricas podem parecer incomuns das métricas normalmente utilizadas pelo marketing e este autor propõe que as métricas sejam administradas em conjunto a fim de formar um sistema deavaliação abrangente.

Nesta pesquisa o foco está no estudo das métricas de marketing aplicadas aos serviços educacionais e as bases das métricas são explicadas de acordo com a sua construção, as considerações a respeito da métrica e o propósito (FARRIS, 2007; DAVIS, 2007).

\section{MÉTRICAS DE GERENCIAMENTO DE PRODUTO E VALOR DAMARCA}

Farris et al. (2007) apresentam mais de 50 métricas de marketing que servem a variados segmentos de mercado e a métrica de valor da marca é apresentada como um dos elementos-chave para o direcionamento das estratégias de marketing. Segundo Barwise e Farley (2004) a métrica mais utilizada pelas organizações é a participação de mercado (market share), conforme descrita no Quadro 2. No ensino superior é uma medida que, por monitorar sinais de mudanças no cenário competitivo, freqüentemente leva a ações estratégicas ou táticas por parte das instituições. As demais métricas também contribuem para o gerenciamento do desempenho de marketing nas organizações, conforme 
se observa nos propósitos descritos do Quadro 2.

Quadro 2: Métricas de gerenciamento de produto e valor de marca

\begin{tabular}{|c|c|c|c|}
\hline MÉTRICA & CONSTRUÇÃO & CONSIDERACCÕES & PROPÓSITO \\
\hline $\begin{array}{l}\text { Número de } \\
\text { matrículas efetivas }\end{array}$ & $\begin{array}{l}\text { É o número efetivo de } \\
\text { matrículas novas do primeiro } \\
\text { período registradas no início } \\
\text { no período letivo. }\end{array}$ & 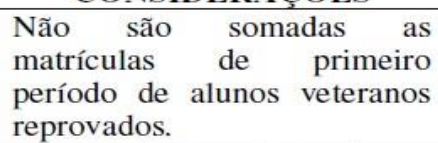 & $\begin{array}{l}\text { Indica a entrada de novos } \\
\text { alunos da IES }\end{array}$ \\
\hline $\begin{array}{ll}\text { Número } & \text { de } \\
\text { inscritos no } & \text { no } \\
\text { processo seletivo }\end{array}$ & $\begin{array}{l}\text { E a quantidade de inscritos } \\
\text { pagantes em um processo } \\
\text { seletivo. }\end{array}$ & $\begin{array}{l}\text { Pode indicar a demanda por } \\
\text { um determinado curso. }\end{array}$ & $\begin{array}{lcc}\text { Mensurar } & \text { o número } & \text { de } \\
\text { pessoas provenientes } & \text { do } \\
\text { processo seletivo. } & \end{array}$ \\
\hline $\begin{array}{l}\text { Participação de } \\
\text { mercado (market } \\
\text { share) }\end{array}$ & $\begin{array}{l}\text { E a porcentagem de um } \\
\text { mercado (definido em termos } \\
\text { de unidades, de receita ou } \\
\text { matrículas de uma IES) } \\
\text { atendido por uma entidade } \\
\text { específica. }\end{array}$ & $\begin{array}{l}\text { Pode não ser uma suposição } \\
\text { razoável se houver diferenças } \\
\text { significativas entre as marcas } \\
\text { concorrentes. }\end{array}$ & $\begin{array}{l}\text { Medir a competitividade do } \\
\text { setor }\end{array}$ \\
\hline $\begin{array}{l}\text { Taxa de conversão } \\
\text { de inscritos versus } \\
\text { matriculados }\end{array}$ & $\begin{array}{l}\text { É a razão entre o número de } \\
\text { inscritos em um processo } \\
\text { seletivo versus o número de } \\
\text { novos matriculados. }\end{array}$ & $\begin{array}{l}\text { É necessário observar que } \\
\text { existem matrículas de } \\
\text { primeiros períodos de } \\
\text { reprovados e não devem ser } \\
\text { somadas ao número de novas } \\
\text { matrículas. }\end{array}$ & $\begin{array}{l}\text { Mede o número das pessoas } \\
\text { que se interessam pela IES } \\
\text { daquelas que concretizam o } \\
\text { compromisso. }\end{array}$ \\
\hline $\begin{array}{l}\text { Taxa de retenção } \\
\text { de alunos }\end{array}$ & $\begin{array}{l}\text { É o número de alunos que } \\
\text { efetivam a re-matrícula. }\end{array}$ & $\begin{array}{l}\text { A retenção refere-se somente } \\
\text { aos alunos existentes em } \\
\text { situações contratuais. }\end{array}$ & $\begin{array}{llr}\text { Mapear mudanças } & \text { na } \\
\text { habilidade da empresa } & \text { em } \\
\text { reter os alunos. } & & \\
\end{array}$ \\
\hline $\begin{array}{ll}\text { Taxa } & \text { de } \\
\text { preenchimento } & \text { de } \\
\text { vagas ofertadas } & \end{array}$ & $\begin{array}{l}\hat{E} \text { a razão entre as vagas } \\
\text { preenchidas e as ofertadas } \\
\text { em um processo seletivo. }\end{array}$ & $\begin{array}{l}\text { Esta taxa indica o resultado } \\
\text { do processo seletivo como um } \\
\text { todo e não avalia } \\
\text { individualmente a demanda } \\
\text { por um curso }\end{array}$ & $\begin{array}{l}\text { Avalia o resultado } \\
\text { processo seletivo. }\end{array}$ \\
\hline $\begin{array}{ll}\text { Tempo } & \text { de } \\
\text { atendimentos } & \text { ao } \\
\text { aluno } & \end{array}$ & $\begin{array}{l}\text { Avalia o tempo de } \\
\text { atendimento de um processo } \\
\text { burocrático de secretaria, } \\
\text { biblioteca ou até uma } \\
\text { informação por telefone. }\end{array}$ & $\begin{array}{l}\text { Cabe a IES determinar os } \\
\text { processos a serem medidos e } \\
\text { indicar o tempo ideal de } \\
\text { atendimento. }\end{array}$ & $\begin{array}{l}\text { Mede a eficiência dos } \\
\text { processos no atendimento ao } \\
\text { aluno ou comunidade. }\end{array}$ \\
\hline $\begin{array}{l}\text { Taxa de sucesso } \\
\text { do aluno e ex- } \\
\text { aluno }\end{array}$ & $\begin{array}{l}\text { É o grau de satisfação do } \\
\text { aluno ou ex-aluno com a sua } \\
\text { empregabilidade } \\
\text { empreendimento. }\end{array}$ & $\begin{array}{l}\text { O grau de satisfação desta } \\
\text { métrica pode ter variações } \\
\text { dependendo dos valores } \\
\text { pessoais do aluno ou ex- } \\
\text { aluno. }\end{array}$ & $\begin{array}{l}\text { Medir a empregabilidade ou } \\
\text { capacidade empreendedora } \\
\text { dos alunos e ex-alunos }\end{array}$ \\
\hline $\begin{array}{l}\text { Métricas de valor } \\
\text { de marca }\end{array}$ & $\begin{array}{l}\text { Pesquisas que identifiquem } \\
\text { os atributos da marca }\end{array}$ & $\begin{array}{l}\text { Métricas que mapeiam a } \\
\text { essência da marca podem não } \\
\text { mapear sua saúde e valor. }\end{array}$ & $\begin{array}{l}\text { Monitorar o valor de uma } \\
\text { marca. A sua imagem e } \\
\text { percepção. }\end{array}$ \\
\hline
\end{tabular}

Fonte: adaptado de Farris et al.(2007)

Medir o valor de uma marca, conforme o propósito descrito no Quadro 3 de monitorar a sua imagem e percepção, identifica o quanto a marca pode ser relevante ou apreciada para um cliente. Existem métodos adotados pelo mercado e gerenciados por algumas empresas que patentearam metodologias. Segundo Aaker, Kumar e Day (1995), uma marca terá alto valor para o consumidor se corresponder ao seu nível esperado de expectativas.

\section{MÉTRICAS DE IMAGEM E PERCEPÇÃO DA MARCA}

Uma IES pode ter certa imagem diante de um público que pode variar de positiva ou negativa, forte ou fraca, boa ou ruim, e isso contribui para a demanda por um curso superior no momento do processo seletivo.

No Quadro 4 observa-se a métrica de satisfação do aluno, que segundo Leite (2006), os alunos atribuem qualidade ao curso mediante uma avaliação baseada em fatores que eles consideram os mais relevantes, entre eles, dois estão diretamente relacionados ao valor da mensalidade paga e um à disposição de professores e funcionários em resolver os problemas apresentados pelos discentes. 
Quadro 3: Métricas de imagem e percepção damarca

\begin{tabular}{|c|c|c|c|}
\hline MÉTRICA & CONSTRUÇÃO & CONSIDERAÇÕES & PROPÓSITO \\
\hline $\begin{array}{l}\text { Índice } \\
\text { satisfação do aluno }\end{array}$ & $\begin{array}{l}\text { Podem ser usados dados do } \\
\text { relatório da Comissão } \\
\text { Própria de avaliação (CPA). }\end{array}$ & $\begin{array}{l}\text { Sujeito à tendenciosidades nas } \\
\text { respostas. } \\
\text { Capta visões dos atuais } \\
\text { clientes, não dos clientes } \\
\text { evadidos. }\end{array}$ & $\begin{array}{l}\text { Relatos de insatisfação } \\
\text { mostram aspectos que } \\
\text { exigem aperfeiçoamento. }\end{array}$ \\
\hline $\begin{array}{l}\text { Penetração } \\
\text { mercado }\end{array}$ & $\begin{array}{l}\text { Compradores } \\
\text { categoria de produto como } \\
\text { porcentagem da população } \\
\text { total. }\end{array}$ & 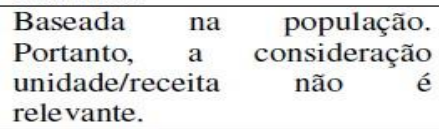 & $\begin{array}{l}\text { Medir a aceitação da } \\
\text { categoria por uma população } \\
\text { definida. }\end{array}$ \\
\hline $\begin{array}{ll}\text { Intenções } & \text { de } \\
\text { estudar na IES } & \end{array}$ & $\begin{array}{l}\text { Probabilidade da intenção de } \\
\text { comprar ou estudar na IES }\end{array}$ & $\begin{array}{l}\text { Estimar a probabilidade de } \\
\text { compra, agregar e analisar } \\
\text { classificações das intenções } \\
\text { declaradas. }\end{array}$ & $\begin{array}{l}\text { Mensurar a disposição pré- } \\
\text { compra. }\end{array}$ \\
\hline $\begin{array}{l}\text { Taxa de retorno a } \\
\text { IES e lealdade }\end{array}$ & $\begin{array}{l}\text { As medidas incluem a } \\
\text { participação nos gastos, } \\
\text { disposição de pagar mais, } \\
\text { disposição para procurar. }\end{array}$ & $\begin{array}{l}\text { A "lealdade" por si só não é } \\
\text { uma métrica formal, mas as } \\
\text { métricas específicas avaliam } \\
\text { aspectos dessa dinâmica. }\end{array}$ & $\begin{array}{l}\text { Indicação de fluxo de receita } \\
\text { futura básica. }\end{array}$ \\
\hline $\begin{array}{l}\text { Taxa de disposição } \\
\text { para indicar }\end{array}$ & $\begin{array}{l}\text { Geralmente medida via } \\
\text { classificações em uma escala } \\
\text { de } 1 \text { a } 5 \text {. }\end{array}$ & Tem impacto não-linear. & $\begin{array}{l}\text { Mostra a força da lealdade, o } \\
\text { impacto potencial sobre os } \\
\text { outros. }\end{array}$ \\
\hline $\begin{array}{l}\text { Número } \\
\text { matérias } \\
\text { imprensa } \\
\text { própria IES } \\
\text { (Clipping) }\end{array}$ & $\begin{array}{l}\text { Número de publicações } \\
\text { jornalísticas com citação da } \\
\text { marca da IES }\end{array}$ & $\begin{array}{l}\text { E avaliado o número e o } \\
\text { conteúdo. Dependendo do } \\
\text { conteúdo da citação pode } \\
\text { haver retratação. }\end{array}$ & $\begin{array}{l}\text { Mensura o quanto a marca é } \\
\text { usada de referência no meio } \\
\text { jornalístico. }\end{array}$ \\
\hline
\end{tabular}

Fonte: adaptado de Farris et al.(2007)

\section{MÉTRICAS DE AÇ̃̃ES PROMOCIONAIS}

As métricas descritas no Quadro 6 referem-se as ações promocionais de uma empresa e devem ser construídas a partir do planejamento de marketing da organização (KOTLER e FOX,1994).

Segundo Hoper (2005), com a mudança na competitividade do setor educacional, as ações devem ser medidas e corrigidas quando necessário. A instituição que utiliza de métricas pode organizá-las de forma em que o tomador de decisões acesse isto de forma rápida e atualizada (PATTERSON,2007).

Quadro 4: Métricas de ações promocionais

\begin{tabular}{|c|c|c|c|}
\hline MÉTRICA & CONSTRUÇÃOO & CONSIDERAÇÕES & PROPÓSITO \\
\hline $\begin{array}{lr}\text { Retorno do } \\
\text { investimento das } \\
\text { mídias }\end{array}$ & $\begin{array}{l}\text { É o número de vezes que cada } \\
\text { mídia foi vista por um aluno } \\
\text { participante do processo } \\
\text { seletivo }\end{array}$ & $\begin{array}{l}\text { Pode haver alunos que } \\
\text { observaram mais de uma } \\
\text { mídia }\end{array}$ & $\begin{array}{l}\text { Aponta para a mídia mais } \\
\text { vista durante uma campanha } \\
\text { de processo seletivos. }\end{array}$ \\
\hline
\end{tabular}

Fonte: adaptado de Farris et al.(2007)

\section{MÉTRICAS FINANCEIRAS E DE RENTABILIDADE DO CLIENTE}

No Quadro 7 são descritas as métricas financeiras e de rentabilidade do cliente. Um dos indicadores mais relevantes ao tópico é o custo médio de aquisição de um cliente que é a razão da despesa de aquisição pelo número de clientes adquiridos (FARRIS et al., 2007; COBRA e BRAGA, 2004).

Reter um cliente é mantê-lo ativo após a sua primeira aquisição. Este cliente já fez parte da métrica de custo de aquisição, pois foi o momento de prospectá-lo. Representa o custo médio para reter um cliente existente e é a razão da despesa de retenção direcionada a um grupo de clientes pelo número dos clientes retidos com sucesso (DAVIS, 2007; FARRIS et al., 2007). 
Quadro 5: Métricas financeiras e de rentabilidade do cliente

\begin{tabular}{|c|c|c|c|}
\hline MÉTRICA & CONSTRUÇÃO & CONSIDERACCÕES & PROPÓSITO \\
\hline $\begin{array}{l}\text { Retorno de um } \\
\text { novo curso }\end{array}$ & $\begin{array}{l}\text { Tempo necessário para que } \\
\text { haja retorno do investimento } \\
\text { inicial de implantação. }\end{array}$ & $\begin{array}{l}\text { Favorece mais os projetos } \\
\text { com retornos rápidos do que o } \\
\text { sucesso de longo prazo. }\end{array}$ & Cálculo de retorno simples. \\
\hline $\begin{array}{lr}\text { Custo médio } & \text { de } \\
\text { captação } & \text { por } \\
\text { matrícula } & \end{array}$ & $\begin{array}{lll}\text { Razão da despesa } & \text { de } \\
\text { aquisição para o número de } \\
\text { novos clientes adquiridos. }\end{array}$ & $\begin{array}{l}\text { Frequentemente é difícil isolar } \\
\text { a despesa de aquisição da } \\
\text { despesa total de marketing. }\end{array}$ & $\begin{array}{l}\text { Mapear o custo da aquisição } \\
\text { de novos clientes e comparar } \\
\text { esse custo com o valor dos } \\
\text { clientes recém-adquiridos. }\end{array}$ \\
\hline $\begin{array}{l}\text { Custo médio de } \\
\text { retenção }\end{array}$ & $\begin{array}{l}\text { Razão da despesa de retenção } \\
\text { para o número de novos } \\
\text { clientes adquiridos. }\end{array}$ & $\begin{array}{l}\text { Frequentemente, é difícil } \\
\text { isolar a despesa de retenção } \\
\text { da despesa total de marketing. }\end{array}$ & $\begin{array}{l}\text { Monitorar as despesas de } \\
\text { retenção por cliente. }\end{array}$ \\
\hline $\begin{array}{l}\text { Ponto } \\
\text { equilíbrio } \\
\text { financeiro }\end{array}$ & $\begin{array}{l}\text { Para ponto de equilíbrio } \\
\text { unitário, dividem-se os custos } \\
\text { fixos pela contribuição por } \\
\text { unidade. }\end{array}$ & $\begin{array}{l}\text { As estimativas de custos } \\
\text { variáveis e fixos podem ser } \\
\text { válidas somente em certas } \\
\text { faixas de vendas e de } \\
\text { produção. }\end{array}$ & $\begin{array}{l}\text { Indicador aproximado da } \\
\text { atratividade projetada e da } \\
\text { habilidade de produzir lucro. }\end{array}$ \\
\hline $\begin{array}{l}\text { Rentabilidade do } \\
\text { cliente }\end{array}$ & $\begin{array}{l}\text { Diferença entre as receitas } \\
\text { obtidas e os custos associados } \\
\text { com a relação com o cliente } \\
\text { durante um período } \\
\text { específico. }\end{array}$ & $\begin{array}{l}\text { Exige que se atribuam receitas } \\
\text { e custos para clientes } \\
\text { individualmente. }\end{array}$ & $\begin{array}{l}\text { Permite que a empresa } \\
\text { identifique quais clientes são } \\
\text { rentáveis e quais não são. }\end{array}$ \\
\hline $\begin{array}{l}\text { Valor de duração } \\
\text { do cliente }\end{array}$ & $\begin{array}{l}\text { O valor atual de futuros } \\
\text { fluxos de caixa atribuídos à } \\
\text { relação com o cliente. }\end{array}$ & $\begin{array}{l}\text { Exige uma projeção de fluxos } \\
\text { de caixa futuros da relação } \\
\text { com um cliente. }\end{array}$ & $\begin{array}{l}\text { Cálculo do tempo em que o } \\
\text { cliente contribui para a } \\
\text { empresa. }\end{array}$ \\
\hline
\end{tabular}

Fonte: adaptado de Farris et al.(2007)

Ao analisar o Quadro 7, pôde-se verificar a variedade de métricas que o gestor pode ter em mãos para analisar as ações de marketing, controle da verba anual e formas financeiras de medir o retorno das ações. As empresas que possuem prática na administração de métricas de marketing determinam as mais importantes a fim de focar em métricas relevantes aos objetivos organizacionais (Hauser e Katz, 1998).

\section{MÉTRICAS DE MARKETING DIGITAL}

Segundo Ledford (2009), na internet existem registrados dois bilhões de páginas da web e é necessário que empresas e organizações que investem em ações de marketing digital para aprimorar seus objetivos, como aumentar o número de visitantes da página, analisem as métricas para tomar decisões.

O marketing digital soma-se a promoção das marcas, que antes do início da web, eram feitos por meio das mídias tradicionais, como televisão, rádio, jornal e outros. Neste meio digital as métricas são analisadas com mais precisão do que em meios de comunicação tradicionais, devido as suas características de conexão em redes e da tecnologia de ferramentas de análise e rastreamento da internet.

Uma das ferramentas utilizadas no marketing digital é o Google Analytics. Esta ferramenta digital pode monitorar o site e fornecer ao administrador da conta os registros das navegações, incluindo uma personalização avançada e análises por segmentação do cliente, fornece informações sobre o perfil dos visitantes e pode comparar dados de investimentos com propagandas, fornece gráficos em movimento e relatórios sobre o conteúdo pesquisado dentro da página. Identifica também as palavras-chave buscadas que podem ter direcionado o visitante a sua página e monitora se o visitante entrou diretamente no seu endereço ou migrou de outra página que estava navegando. 0 gestor pode consultar diversas informações sobre a visitação do site para usar de base nas tomadas de decisões de marketing digital.

Em comparação com a comunicação tradicional de rádio e televisão, o marketing digital possui termos específicos de análises, tais como: cliques, visitantes e abandono de página. O Quadro 8 apresenta 
algumas métricas de marketing digital.

Quadro 6: Métricas de marketing digital

\begin{tabular}{|c|c|c|c|}
\hline MÉTRICA & CONSTRUÇÃO & CONSIDERAÇÕES & PROPÓSITO \\
\hline $\begin{array}{l}\text { Exposições de um } \\
\text { anúncio }\end{array}$ & $\begin{array}{l}\text { Uma exposição é gerada cada } \\
\text { vez que um anúncio é visto. }\end{array}$ & $\begin{array}{l}\text { Como métrica, as exposições } \\
\text { não explicam a qualidade do } \\
\text { que é visto. }\end{array}$ & $\begin{array}{l}\text { Identificar quantas vezes um } \\
\text { anúncio é visto. }\end{array}$ \\
\hline $\begin{array}{l}\text { Custo por mil } \\
\text { exposições }\end{array}$ & $\begin{array}{l}\text { Custo de propaganda dividido } \\
\text { pelas exposições geradas (em } \\
\text { milhares). }\end{array}$ & $\begin{array}{l}\text { E uma medida de custo por } \\
\text { exposição de comercial, } \\
\text { representando as exposições } \\
\text { em milhares. }\end{array}$ & $\begin{array}{l}\text { Mensurar a eficácia de custo } \\
\text { na geração de exposições. }\end{array}$ \\
\hline Freqüência média & $\begin{array}{l}\text { Número médio de vezes que } \\
\text { um indivíduo recebe um } \\
\text { comercial, desde que ele } \\
\text { realmente seja exposto à } \\
\text { propaganda. }\end{array}$ & $\begin{array}{l}\text { A freqüência é medida } \\
\text { somente entre pessoas que de } \\
\text { fato vêem o anúncio que está } \\
\text { sendo estudado. }\end{array}$ & 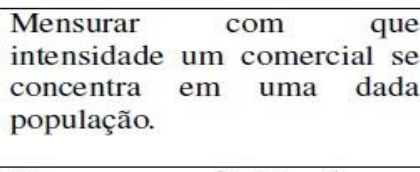 \\
\hline Taxa de cliques & $\begin{array}{lrrr}\text { Número de } & \text { cliques } & \text { como } \\
\text { fração do número } & \text { de } \\
\text { exposições. } & & \\
\end{array}$ & $\begin{array}{l}\text { Medida interativa } \\
\text { propaganda na Web. }\end{array}$ & $\begin{array}{l}\text { Mensurar a eficácia de um } \\
\text { anúncio na Web. }\end{array}$ \\
\hline Custo por clique & \begin{tabular}{lll} 
Custo de & \multicolumn{2}{c}{ propaganda, } \\
dividido pelo número de \\
cliques gerados.
\end{tabular} & $\begin{array}{l}\text { Freqüentemente usado como } \\
\text { mecanismo de cobrança. }\end{array}$ & $\begin{array}{l}\text { Mensurar ou estabelecer a } \\
\text { eficácia de custo de um } \\
\text { comercial. }\end{array}$ \\
\hline $\begin{array}{l}\text { Page views ou } \\
\text { impressões }\end{array}$ & $\begin{array}{l}\text { Número total de vezes que } \\
\text { uma página é visualizada } \\
\text { pelos Internautas. }\end{array}$ & $\begin{array}{l}\text { Exemplo: } 4 \text { milhões de page } \\
\text { views significa que a página } \\
\text { foi aberta } 4 \text { milhões de vezes. }\end{array}$ & $\begin{array}{l}\text { Identificar quantas vezes a } \\
\text { página está sendo acessada. }\end{array}$ \\
\hline Visitas únicas & $\begin{array}{l}\text { Número de visualizações } \\
\text { individuais de um site da } \\
\text { Web. }\end{array}$ & $\begin{array}{l}\text { Diferente da métrica page } \\
\text { views, mede o número de } \\
\text { visitas únicas. }\end{array}$ & $\begin{array}{l}\text { Mensurar o tráfego de } \\
\text { público em um site da Web. }\end{array}$ \\
\hline
\end{tabular}

Fonte: adaptado de Farris et al.(2007)

No ensino superior pode-se utilizar o portal web de uma IES para criar relacionamento com o aluno, o ex-aluno e informar os acontecimentos da instituição (COBRA e BRAGA, 2004; LEITE, 2006). Os alunos que irão ingressar em um ensino superior buscam informações na internet sobre referências da IES e isto pode ser monitorado pelos gestores de marketing por meio de ferramentas de internet específicas. Essas buscas podem oferecer informações importantes a respeito do curso mais procurado ou da instituição mais pesquisada na internet (LEDFORD, 2009).

As métricas de marketing tem sido um tema em constante evolução desde as suas primeiras publicações na década de 1980. Neste capítulo foram apresentadas as teorias dos autores que contribuíram para o tema e também as métricas que são utilizadas nos diversos setores da economia. A organização das métricas no formato de painéis de controle tem sido um facilitador para os gestores da área. Por fim, foram apresentadas formas de mensuração de mídias web, as quais possuem mais precisão que as tradicionais e isto também serve de contribuição para a ampliação dos estudos relacionados ao tema.

\section{MÉTODO}

O presente estudo foi estruturado a fim de identificar quais as métricas mais comuns de marketing e como são utilizadas na gestão de Instituições de Ensino Superior privadas em Curitiba. A primeira fase da pesquisa ocorreu por meio de consulta a materiais publicados que abordam temas relacionados ao da pesquisa. Assim, foram consultados livros, periódicos internacionais, relatórios técnicos e páginas da Internet, como fontes de informação, para posterior análise com os dados obtidos.

A pesquisa classifica-se como exploratória, pois tem o "objetivo de proporcionar maior familiaridade com o problema, com vistas a torná-lo mais explícito" (GIL, 2002). Utilizou-se como método de coleta de dados a entrevista de profundidade conceituada como "uma entrevista não estruturada, direta, pessoal, em que um único respondente é testado por um entrevistador altamente treinado, para descobrir motivações, crenças, atitudes e sensações subjacentes sobre um tópico" (MALHOTRA, 2001).

Foram realizadas entrevistas de profundidade com oito profissionais dirigentes de marketing de IES privadas, sendo que a maioria possui em torno de 10 anos de atuação profissional na área. As IES dos 
entrevistados foram classificadas em pequeno (mais que 2.000 matriculados), médio (mais que 2.000 e menos que 8.500 matriculados) e grande porte (mais que 8.500 matriculados), determinadas pelo número de matrículas no início dos anos letivos, de acordo com dados do Censo de Educação Superior 2008 (INEP, 2009a). As entrevistas consistiram em um roteiro semi-estruturado, realizada pelo autor da dissertação, com duração variável de 40 minutos a 1 hora e 20 minutos.

As instituições do presente estudo foram classificadas por ordem de porte de alunos matriculados e identificadas pelas letras A, B, C, D, E, F, G e H, como descrito na Tabela 1.

Tabela 1: Identificação das IES pelo número dematrículas

\begin{tabular}{|c|c|c|}
\hline Identificação & Porte & No. de Matriculados \\
\hline IES A & Grande Porte & mais que 8.500 \\
\hline IES B & Grande Porte & mais que 8.500 \\
\hline IES C & Grande Porte & mais que 8.500 \\
\hline IES D & Médio Porte & mais que $2.000 /$ menos que 8.500 \\
\hline IES E & Médio Porte & mais que $2.000 /$ menos que 8.500 \\
\hline IES F & Médio Porte & mais que $2.000 /$ menos que 8.500 \\
\hline IES G & Pequeno Porte & menos que 2.000 \\
\hline IES H & Pequeno Porte & menos que 2.000 \\
\hline
\end{tabular}

\section{COLETA DE DADOS}

Os oito entrevistados foram previamente contatados por telefone para agendar as entrevistas, realizadas em seus próprios ambientes de trabalho. As entrevistas de profundidade foram realizadas individualmente, pelo próprio pesquisador, cujos dados eram registrados manualmente e por meio de gravador de áudio (quando autorizado pelo entrevistado). O período de coleta de dados foi de aproximadamente quatro meses, pelo grau de dificuldade e disponibilidade de agendamento com os profissionais.

Os entrevistados receberam informações prévias sobre a natureza do trabalho, forma de divulgação dos resultados e garantia de anonimato. Também lhes foi assegurada total liberdade para se recusarem a participar ou se retirar da pesquisa a qualquer momento, sendo que ao concordarem em participar assinaram um Termo de Consentimento Livre eEsclarecido.

\section{PREPARAÇÃO DO ROTEIRO DE ENTREVISTA}

A preparação do roteiro de entrevista seguiu as seguintes etapas: o planejamento da entrevista; a escolha dos entrevistados, que eram pessoas com familiaridade ao tema pesquisado; a oportunidade da entrevista, ou seja, a disponibilidade do entrevistado em fornecer a entrevista; as condições favoráveis que garantiram ao entrevistado o segredo de suas confidências e de sua identidade e, por fim, a preparação específica que consistiu em organizar o roteiro com as questões mais importantes (LAKATOS, 1996).

Pelas duas primeiras entrevistas selecionou-se as questões de maior relevância ao tema em estudo. Assim, as perguntas eram feitas levando-se em conta a seqüência do pensamento do entrevistado, ou seja, procurando dar continuidade na conversação, conduzindo a entrevista com certo sentido lógico para o entrevistado.

\section{PROCEDIMENTOS PARA ANÁLISE DAS ENTREVISTAS}

Todas as entrevistas tiveram gravação autorizada e, posteriormente, foram transcritas, o que possibilitou a análise de conteúdo de forma mais minuciosa e a transcrição de alguns trechos ao longo da dissertação. Nas transcrições o entrevistador foi denominado pesquisador e os entrevistados, independente do gênero masculino ou feminino, denominados gestores entrevistados 


\section{RESULTADOS}

A primeira avaliação foi sob a origem do departamento nas IES e o tempo de existência deste departamento na IES, com o objetivo de saber sobre a experiência que possuem na aplicação do marketing dentro dos serviços educacionais. 0 segundo item deste capítulo analisa as funções do departamento e suas responsabilidades. Na seqüência é avaliado o conhecimento e uso das métricas de marketing pelos gestores das IES pesquisadas. Para concluir o capítulo da análise dos resultados as métricas de marketing mais comuns usadas nas IES foram inseridas no Quadro 10.

\section{O DEPARTAMENTO DE MARKETING NAS IES}

A primeira análise refere-se ao departamento de marketing como o seu tempo de existência e experiência no segmento, as suas funções e atividades mais comuns e a responsabilidade pelo desempenho da instituição.

Os depoimentos mostraram que a gestão de marketing organizada em um departamento é algo novo para todas as instituições pesquisadas. Foi identificado predominância na pré-existência de ações de marketing e comunicação, mas não de uma forma organizada com um departamento próprio, tarefas claras e metas estabelecidas. Estas tarefas misturavam-se a outros departamentos e o desempenho poderia estar sob responsabilidade de uma área que poderia ter outras prioridades.

Alguns autores já apontavam que o mercado educacional estava passando por alterações e as IES deveriam dar atenção a questões de estratégia, promoção, da propaganda e da criação de programas de relacionamento com os alunos, ex-alunos e comunidade (KOTLER e FOX, 1994; COBRA e BRAGA, 2004; BRAGA, 2005).

No Brasil, a profissionalização de marketing no setor educacional passou a ser implantada nos últimos dez anos. Em média as IES pesquisadas mostram seis anos de fundação de um departamento de marketing estruturado e dirigido por um profissional. Esta profissionalização ocorreu a partir do ano 2000 devido à necessidade das IES se adaptarem ao crescimento do número de concorrentes, do número de cursos e da demanda que se manteve estável (PORTO, 2003; HOPER, 2005; MONTEIRO, 2009; INEP, 2009a).

As IES passaram a praticar marketing de forma semelhante ao das indústrias e outros setores (HOPER, 2005). Porém, os gestores entrevistados nesta pesquisa demonstraram que ainda não é uma realidade usar o marketing como ferramenta de pesquisa, desenvolvimento de novos cursos, estimativa de demandas e produzir comunicação que gere valor à marca. Na maior parte das ações de marketing são usadas para anunciar o processo seletivo (Vestibular).

Um resultado positivo pode estar ligado ao alcance da divulgação de um processo seletivo e em outra IES pode estar ligado à rentabilidade do cliente a longo prazo. Isto foi observado na literatura em análises de indicadores subjetivos e objetivos (PERIN, SAMPAIO, 2006).

\section{A RESPONSABILIDADE DO MARKETING PELO DESEMPENHO DAIES}

O marketing possui responsabilidades específicas e pode ser dirigido operacionalmente ou estrategicamente por uma organização e também podem ser atribuídos resultados de desempenho do produto ao marketing (KOTLER e KELLER, 2005). Na visão de alguns gestores das IES pesquisadas é necessário especificar o que vem a ser este desempenho baseado nas responsabilidades que são atribuídas por uma direção superior.

Dentro das ações de marketing, a campanha de divulgação do Vestibular que é responsável pela captação de novos alunos e novas matrículas e conseqüentemente pelas receitas financeiras, tem sido a ação de maior visibilidade pelos gestores. 0 marketing é visto em muitas organizações como um setor de apoio às vendas ou ainda um articulador do gerenciamento da propaganda (CAMPOMAR, 
2006).

Sobre as funções e atividades do departamento de marketing foi identificado que existem no dia a dia dos departamentos as funções táticas e estratégicas. Em algumas IES pesquisadas o marketing é tratado como uma agência de propaganda que conduz os trabalhos de criação e produção. Conforme os autores pesquisados, desde a década de 1980 já era sinalizada a necessidade de organizar o marketing de maneira profissional, mais precisa e que ofereça à gestão informações mais técnicas daquilo que está sendo feito e planejado (WEBSTER, 1981; SRIVASTAVA et al.,1998).

Com o intuito de conhecer as responsabilidades do marketing os gestores entrevistados foram questionados se existem responsabilidades diferentes sendo executadas em outras IES e a resposta de todos os gestores foi negativa. As IES possuem responsabilidades semelhantes uma das outras, conforme apresentadas no Quadro 9, o qual mostra algumas das responsabilidades do marketing e divididas entre o que é operacional e estratégico (KOTLER e KELLER, 2005; CAMPOMAR,2006).

Quadro 7: Atividades táticas e estratégicas do marketing nas IES

\begin{tabular}{ll}
\hline Operacional & Estratégico \\
\hline Execução de eventos & Criação da estratégia de divulgação \\
Apoio ao atendimento dos vestibulandos & Criação de estratégias promocionais \\
Visita acompanhada ao campus & Criação de um Plano de mídia \\
Ações de panfletagem & Criação de peças publicitárias \\
Desenho de materiais para comunicação & \\
\hline
\end{tabular}

Na entrevista com o gestor da IES H pôde-se observar uma resposta abrangente daquilo que alguns autores consideram como funções estratégicas dos departamentos de marketing das IES. Estas funções podem colaborar para o desenvolvimento de novos cursos e melhorar a percepção da qualidade do serviço educacional (COBRA e BRAGA, 2004; BRAGA, 2005).

" ... a principal responsabilidade do marketing é fazer uma leitura do mercado, identificar as oportunidades, as tendências, o marketing é muito confundido com publicidade e propaganda e isso talvez seja apenas um dos pês, mas tem que considerar, que todos os outros são muito importantes, mas o marketing está mais voltado a trabalhar com a inteligência, mais informação e não simplesmente operacionalizando uma campanha, uma ação promocional." Gestor de marketing da IES H

\section{O CONHECIMENTO E USO DE MÉTRICAS DE MARKETING PELOS GESTORES DAS IES}

As entrevistas demonstraram que os gestores de marketing das IES conhecem as funções e responsabilidades do marketing, porém medir os resultados não é algo comum nas gestões ou tem sido praticado mais tecnicamente nos últimos cincoanos.

Segundo Hauser e Katz (1998) uma organização só pode administrar com competência aquilo que pode medir. 0 domínio das métricas de marketing pelo gestor é algo que está em evidência nas organizações (AMBLER, 2000).

$\mathrm{Na}$ entrevista com o gestor da IES C foi observado que o reconhecimento e a responsabilidade (apenas comunicar ou divulgar um processo seletivo) do marketing deveriam ser maiores por parte da direção geral das instituições. Nesta entrevista (IES C) isto ficou claro, pois o entrevistado espera que o marketing atenda a essas funções mais nobres, que podem contribuir para a construção de um novo curso, por exemplo (SOLOMON, 2002; COBRA e BRAGA, 2004; CAMPOMAR, 2006).

" ... hoje nosso departamento cuida só da parte de divulgação, acaba que os coordenadores e diretores não têm uma cultura de marketing, assim, eles dizem: Estou querendo abrir um tecnólogo! E, o certo seria montar uma pesquisa para saber a demanda de mercado, as necessidades, o preço e a concorrência. Então, o que estou 
tentando conscientizar é essa mentalidade de marketing, é participar das decisões..." Gestor de marketing da IES C

Em relação ao conhecimento de métricas de marketing todos os gestores se mostraram conhecedores e receptivos sobre o assunto, nem sempre em métricas formais e detalhadas, mas reconhecem a importância da mensuração das atividades de marketing. Os gestores sabem que a questão das métricas e o seu uso formal é algo recente, que não é uma prática que se implanta rapidamente, existe um processo que sofre alterações e aperfeiçoamentos com o tempo (WEBSTER, 1981; AMBLER, 2000; PATTERSON, 2007).

\section{AS MÉTRICAS DE MARKETING MAIS COMUNS NASIES}

0 resultado das entrevistas com os gestores em relação às métricas de marketing mais comuns é apresentado no Quadro 10 e o que se identificou foi que somando todas as métricas chegou-se ao número de 18 métricas mais comuns, mas ao analisar as métricas usadas em comum por todos os gestores reduzem-se a um número de cinco. As IES têm que estar atentas à relevância das métricas e não a sua quantidade, portanto, cada gestor deve considerar quais são as métricas necessárias para medir o retorno das atividades de marketing (HAUSER e KATZ,1998).

O Quadro 10 apresenta as 18 métricas mais usadas na gestão de marketing de IES e observa-se que as cinco primeiras métricas são usadas por todas as IES, sendo, portanto, consideradas as mais comuns.

Quadro 8: As métricas mais comuns na gestão de marketing educacional

\begin{tabular}{|c|c|c|c|c|c|c|c|c|}
\hline Métrica & 旓 & $\stackrel{0}{\infty}$ & 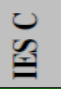 & 忿 & $\stackrel{0}{=}$ & $\stackrel{\vec{I}}{=}$ & 吕 & 可 \\
\hline Número de matrículas efetivas & $\mathrm{X}$ & $\mathrm{x}$ & $\mathrm{X}$ & $\mathrm{X}$ & $\mathrm{x}$ & $\mathrm{x}$ & $\mathrm{X}$ & $\mathrm{X}$ \\
\hline Taxa de conversão (inscritos $\mathrm{x}$ matrículas) & $\mathrm{X}$ & $\mathrm{x}$ & $\mathrm{X}$ & $\mathrm{X}$ & $\mathrm{x}$ & $\mathrm{x}$ & $\mathrm{x}$ & $\mathrm{X}$ \\
\hline Retorno do investimento das Mídias & $\mathrm{X}$ & $\mathrm{x}$ & $\mathrm{X}$ & $\mathrm{X}$ & $\mathrm{x}$ & $\mathrm{x}$ & $\mathrm{X}$ & $\mathrm{X}$ \\
\hline Número de inscritos no processo seletivo & $\mathrm{x}$ & $\mathrm{x}$ & $\mathrm{x}$ & $\mathrm{x}$ & $\mathrm{x}$ & $\mathrm{x}$ & $\mathrm{X}$ & $\mathrm{x}$ \\
\hline Índice de satisfação do aluno & $\mathrm{x}$ & $\mathrm{x}$ & $\mathrm{X}$ & $\mathrm{x}$ & $\mathrm{X}$ & $\mathrm{x}$ & $\mathrm{x}$ & $\mathrm{x}$ \\
\hline Custo médio de captação por matrícula & $\mathrm{X}$ & $\mathrm{x}$ & - & $\mathrm{X}$ & $\mathrm{X}$ & $\mathrm{X}$ & $\mathrm{X}$ & $\mathrm{X}$ \\
\hline Taxa de demanda por curso & $\mathrm{X}$ & $\mathrm{x}$ & $\mathrm{X}$ & - & - & - & $\mathrm{X}$ & $\mathrm{X}$ \\
\hline Investimento em propaganda (orçamento anual) & $\mathrm{X}$ & $\mathrm{x}$ & $\mathrm{X}$ & - & - & - & $\mathrm{X}$ & $\mathrm{X}$ \\
\hline Métricas de web (Google analytics) & $\mathrm{x}$ & $\mathrm{x}$ & - & $\mathrm{X}$ & $\mathrm{X}$ & - & - & - \\
\hline Taxa de retenção de alunos & $\mathrm{x}$ & $\mathrm{x}$ & $\mathrm{x}$ & - & - & - & $\mathrm{X}$ & - \\
\hline Taxa de preenchimento de vagas ofertadas & $\mathrm{X}$ & - & $\mathrm{x}$ & - & - & - & - & $\mathrm{X}$ \\
\hline $\begin{array}{l}\text { Número de matérias na imprensa da própria IES - } \\
\text { (Clipping) }\end{array}$ & $\mathrm{X}$ & & $\mathrm{X}$ & - & - & - & - & - \\
\hline Taxa de retorno e lealdade & $\mathrm{X}$ & - & - & $\mathrm{X}$ & - & - & - & - \\
\hline Taxa de disposição para indicar & $\mathrm{X}$ & - & - & - & - & $\mathrm{x}$ & - & - \\
\hline $\begin{array}{l}\text { Número de matérias na imprensa da concorrência - } \\
\text { (Clipping) }\end{array}$ & $\mathrm{X}$ & - & - & - & - & - & - & - \\
\hline Taxa de transferências (entradas e saídas) & - & - & $\mathrm{X}$ & - & - & - & - & - \\
\hline Tempo de atendimentos ao aluno & - & - & - & - & - & - & $\mathrm{X}$ & - \\
\hline $\begin{array}{l}\text { Taxa de sucesso (empregabilidade) do aluno e ex- } \\
\text { aluno }\end{array}$ & - & - & - & - & $X$ & - & - & - \\
\hline
\end{tabular}

( X ): usa a métrica; ( - ): não usa a métrica

São diversas as métricas de marketing a serem utilizadas por uma organização (DAVIS, 2007), cabe ao gestor escolher as que lhe proporcionarão informações relevantes para apoio na tomada de decisões.

Quando questionados em relação ao surgimento de novas métricas e outros indicadores capazes de 
mostrar o retorno sobre o investimento em marketing não houve resposta que pudesse indicar novidades, mas ficou evidente o uso e aperfeiçoamento das já utilizadas. Segundo Leite (2006) a satisfação do aluno está em receber da IES aquilo que ele esperava. Para os gestores, medir a satisfação do aluno é algo complexo, conforme observado nos trechos das entrevistas das IES A, C e E. Entretanto, a utilização dos relatórios da comissão própria de avaliação (CPA) capta as principais informações em relação à qualidade, pois avalia a infraestrutura, o projeto pedagógico e a qualidade do corpo-docente.

No trecho da IES C o entrevistado reforça sobre o uso do marketing não só na comunicação, mas na construção de um novo curso, nas pesquisas de satisfação do aluno. Com isso, entende-se que novas métricas podem surgir para mensurar o desempenho do marketing. 0 trecho abaixo reforça a importância do papel de marketing na organização, esta visão reflete o que o mercado aponta como mudanças na gestão de marketing das IES (BRAGA et al., 2005; ALMEIDA, 2007)

" ... implantar uma estrutura para conscientizar que em todos os processos decisórios o marketing deve participar, porque o marketing tem que participar da elaboração, por exemplo, de um curso, e não só da divulgação do curso. " Gestor de marketing da IES C

Neste contexto, a análise das entrevistas contribuiu para mostrar o quanto é conhecido pelos gestores o assunto métricas de marketing e quais são as mais usadas na gestão do ensino superior. Contribuiu também para mostrar quais as reais funções dos departamentos de marketing na prática e quais são as funções desejáveis pelos gestores, para poderem oferecer melhores resultados à instituição, como pesquisas e estudos da demanda.

\section{CONSIDERAÇÕES FINAIS}

As principais considerações a respeito do tema são apresentadas após a finalização da pesquisa bibliográfica e a análise das transcrições das entrevistas com os gestores das instituições escolhidas. Assim, foi observado que o conhecimento empírico existe antes do avanço das técnicas, mas se fazem necessários o uso de métodos concretos, organizados e documentados. E verificou-se que essas ações começaram a ser praticadas nos últimos cinco anos pela maioria das instituições pesquisadas e a tendência é que exista maior desenvolvimento das práticas de gestão e mensuração. Os posicionamentos a respeito do método usado para dirigir os departamentos são divergentes entre alguns gestores. Há os que não se responsabilizam pelo resultado da IES e outros que consideram como uma atividade de alta relevância para o resultados dasmatrículas.

A respeito das métricas mais usadas e conhecidas, foram identificadas 18 , conforme apresentadas no Quadro 10, e cinco delas são usadas por todas as instituições, que são: número de matrículas efetivas; taxa de conversão (inscritos x matrículas); retorno do investimento das mídias; número de inscritos no processo seletivo e o índice de satisfação do aluno. Uma sexta métrica foi considerada como mais comum por sete dentre os oitos gestores entrevistados, portanto também considerada como mais usada.

Foi identificado nesta pesquisa que a literatura sobre métricas de marketing começou a ser estudada com profundidade a partir da década de 1980 e que não foi possível localizar até a conclusão desta pesquisa, bibliografia sobre o uso de métricas no ensino superior. Por mais que identificadas métricas para o gerenciamento de serviços, nada foi abordado em relação à gestão de instituições educacionais. Então, conclui-se que o conhecimento teórico a respeito do tema foi considerado em construção.

Em relação ao conhecimento, desenvolvimento e uso das métricas de marketing nas IES, foi identificado que existe por parte dos gestores este conhecimento e uso das métricas. Sobre o desenvolvimento, há escassez no apoio teórico sobre o tema, portanto os gestores estão atuando e utilizando as métricas de acordo com as necessidades, exigências das diretorias da instituição ou para o uso próprio do departamento. 
Em relação ao uso das métricas aplicadas aos serviços educacionais pode-se afirmar que estão sendo utilizadas de maneira simples, sem o uso de ferramentas avançadas ou de painéis de controle. Na entrevista com a IES B foi identificado que já deram início a um processo de formalização do uso das métricas e também o gestor entrevistado relatou que isto ocorre para atender a uma necessidade da direção geral, já na IES D também há um início da concretização e formalização dos processos de mensuração, mas o gestor afirmou que a maioria das métricas serão para o uso do departamento, pois a direção geral não apontou como prioridade o uso de métricas para a gestão.

Todos os gestores entrevistados demonstraram conhecimento, interesse e afinidade pelo assunto por ser algo que já estavam perseguindo devido as modificações do cenário do mercado do ensino superior. Comparativamente entre as IES, pode-se afirmar que duas delas se destacaram por apresentarem propostas e ferramentas mais concretas a respeito de métricas de marketing. As demais IES, demonstraram que conhecem e utilizam as métricas, mas não apontaram formalmente como usam isto. Estas métricas não formalizadas são construídas e analisadas sob demanda para servir de base a um novo planejamento de marketing. Então, em certos períodos a IES pode não ter as métricas atualizadas devido esta falta de formalização no processo e isto pode ocorrer por não utilizarem um painel de controle de marketing.

Conclui-se que as métricas de marketing fazem parte das gestões das IES, mas se encontram em evolução, para a formalidade e o uso comum do segmento, e que os gestores são os principais responsáveis por colaborar com o estudo das métricas para uma construção sólida junto à academia.

\section{SUGESTÕES PARA FUTURAS PESQUISAS}

As futuras pesquisas servirão para aprimorar o tema que, desde a década de 1980, passou a ser discutido e pesquisado de uma forma mais aprofundada (AMBLER, 2000). As sugestões para pesquisas futuras são: Pesquisar a eficácia do uso dos painéis de controle de marketing; Pesquisar sobre o uso de novas métricas para as IES; Comparar o desempenho de instituições que usam métricas de marketing com instituições que não usam; Pesquisar a evolução do conhecimento e uso de métricas de marketing em outros setores da economia;

Por fim, a sugestão de novas pesquisas levam os pesquisadores da área a darem continuidade daquilo que passou a ser relevante na gestão profissional de marketing e que o mercado exige com mais rigor, pois os gestores de marketing precisam conhecer e saber utilizar métodos mais aprimorados de mensuração em marketing para avaliar o seu desempenho e o do setor que dirige (WEBSTER, 1981; HAUSER e KATZ, 1998; CLARK, 1999; AMBLER, 2000; AMBLER e KOKKINAKI, 2004; BARWISE, 2004; PATTERSON, 2007).

\section{REFERÊNCIAS}

AAKER, David A.; KUMAR, V.; DAY, George S. Marketing Research. 5. ed. New York: John Wisley \& Sons, 1995, $782 \mathrm{p}$.

ALMEIDA, A. L. S. de. 0 conhecimento e a importância das métricas de marketing para gestores de médias e grandes empresas brasileiras. 2007. 171f. Dissertação (Mestrado em Administração e Negócios) - Faculdade deAdministração, Contabilidade e Economia, PUCRS, Porto Alegre.

AMBLER, T. Marketing Metrics. Business Strategy Review. v. 11, n. 2, p. 59-66, 2000.

T.; KOKKINAKI, F. et al. Assessing Marketing Performance: Reasons for Metrics Selection. Journal of Marketing Management. v. 20, n. 3/4, p. 475-498, 2004.

BARWISE, P.; FARLEY, J. U. Marketing Metrics: Status of Six Metrics in Five Countries. European Management Journal. v. 22, n. 3, p. 257-262, 2004.

BONI, V.; QUARESMA, S. J. Aprendendo a entrevistar: como fazer entrevistas em Ciências Sociais. Revista Eletrônica dos Pós-Graduandos em Sociologia Política da UFSC. v.2, n 1 (3), p. 68-80, 2005. 
BOSSIDY, L.; CHARAN, R. Execução: a disciplina para atingir resultados. Rio de Janeiro: Elsevier, 2005.

BRAGA, Ryon et al. Análise Setorial do Ensino Superior Privado no Brasil Tendências e Perspectivas 2005-2010. Brasil: Editora Hoper, 2005.

CAMPOMAR, M. C.; IKEDA, A. A. Falácias em Marketing no Brasil. EMA. Curitiba, 2006.

CLARK, B. H. Marketing Performance Measures: History and Interrelationships. Journal of Marketing Management .v. 15, n. 8, p. 711-732, 1999.

COBRA, M.; BRAGA, R. Marketing Educacional. São Paulo: Editora Marcos Cobra, 2004.

DAVIS, J. Measuring Marketing: 103 key metrics every marketer needs. Singapore (Asia), John Wiley \& Sons (Asia) Pte Ltd, 2007.

DESHPANDÉ, R.; FARLEY, J. U.; WEBSTER Jr, F. E. Corporate Culture Customer Orientation, and Innovativeness in Japanese Firms: A Quadrad Analysis. Journal of Marketing. v.57, n.1, p. 23-37, 1993.

FACÓ, M. Propaganda impressa de serviços educacionais: uma investigação sobre o impacto da fotografia das instalações e do testemunhal nas atitudes dos consumidores. 2006. 136f. Dissertação (Mestrado em Administração) - EBAPE, Escola Brasileira de Administração Pública e de Empresas, Rio de Janeiro.

FARRIS, P. W. B.; NEIL T.; PFEIFER, P. E.; REIBSTEIN, D. J. Métricas de Marketing: mais de 50 métricas que todo executivo deve dominar. Porto Alegre: Bookman, 2007.

GIL, A. C. Como elaborar projetos de pesquisa. 4.ed. São Paulo: Atlas, 2002.

GOOGLE. Painel de controle (Dashboard) - Google Analytics. (Conta/Domínio: www.pupo.adm.br) Disponível em: < http://www.google.com.br/analytics>. Acesso em 24 de fevereiro de 2010.

GRINBERG, C. S. Marketing Metrics - Um estudo exploratório sobre a construção do conhecimento de um novo tema em Marketing. 2001. 125f. Dissertação (Mestrado em Administração - Marketing) Universidade Federal do Rio Grande do Sul - UFRGS, Porto Alegre.

HAUSER, J.; KATZ, G. Metrics: You are what you measure! European Management Journal. v. 16, p. 517-528, 1998.

INEP, Instituto Nacional de Estudos e Pesquisas Educacionais Anísio Teixeira. Censo da Educação Superior 2003. Ministério da Educação MEC. Brasília, DF,2003.

. Censo da Educação Superior 2008. Ministério da Educação MEC. Brasília, DF, 2009a.

Divulgado o Censo da Educação Superior 2008, 27/09/2008. Disponível em: <http://www.inep.gov.br/imprensa/noticias/ censo/superior/ news09_05.htm>. Acesso em 27 de novembro de 2009b.

KOHLI, A. ; JAWORSKI, K. B. J. ; KUMAR, A. MARKOR: A Measure of Market Orientation. Journal of Marketing Research. v. 30, n. 4, p. 467-477, 1993.

KOTLER, P.; FOX, K. Marketing estratégico para instituições educacionais. São Paulo, Editora Atlas, 1994.

KOTLER, P.; KELLER, K. Administração de Marketing. 12.ed. São Paulo: Prentice-Hall, 2005.

LAKATOS, E. M.; MARCONI, M. A. Técnicas de pesquisa. 3.ed. São Paulo: Editora Atlas, 1996.

LEDFORD, J. et al. Google analytics. 3.ed. Indianapolis: Wiley publishing, Inc., 2009.

LEITE, R. S. L.; GARCIA, H. E.; LEITE, D. S. A qualidade percebida no ensino superior: um estudo em uma instituição do centro-oeste de Minas Gerais. EnANPAD. Salvador / BA - Brasil,2006.

LOVELOCK, C.; WRIGHT, L. Serviços, marketing e gestão. São Paulo: Saraiva, 2001.

MALHOTRA, N. K. Pesquisa de Marketing: Uma Orientação Aplicada. 3.ed. Porto Alegre: Bookman, 
2001.

Marketing Science Institute. The 1998-2000 Research Priorities. MSI Research. 1998.

The 2000-2002 Research Priorities - Guide to MSI research programs and procedures. MSI Research: Massachusetts, 2000.

. The 2006 - 2008 Research Priorities - Guide to MSI research programs and procedures. MSI Research: Massachusetts, 2006.

MELLO, Clayton. Setor de Marketing direto movimenta R\$17,4 bilhões. Gazeta Mercantil, São Paulo, 01 abril 2008. Caderno C - p. 9.

MÍDIA DADOS. Ibope Monitor. São Paulo, Grupo de Mídia São Paulo. 2005.

Ibope Monitor. São Paulo, Grupo de Mídia São Paulo. 2007.

MONTEIRO, C. Estudos de Mercado - Brasil, Paraná, Curitiba. Brasil: Editora: CM - Consultoria, 2009.

MORAES, W. F. A. Administração estratégica e performance de grandes empresas brasileiras. EnANPAD. Foz do Iguaçu, 1998.

PARASURAMAN, A.; ZEITHAML, V. A.; BERRY, L. A conceptual model of service quality and its implications for future research. Journal of Marketing. v. 49, p. 41- 50,1985.

PATTERSON, L. Taking on the metrics challenge. Journal of Targeting, Measurement \& Analysis for Marketing. v. 15, n. 4, p. 270-276, 2007.

PERIN, M. G.; SAMPAIO, C. H. Performance Empresarial: Uma comparação entre indicadores subjetivos e objetivos. EnAnpad. Foz do Iguaçu, 1999.

PORTO, C.; RÉGNIER, K. O Ensino Superior no Mundo e no Brasil - Condicionantes, Tendências e Cenários para o Horizonte 2003-2025: Uma Abordagem Exploratória. Brasília: Macroplan, 2003.

Queiroz, M. J. de. Métricas de desempenho de marketing em empresas brasileiras. 2009.188f. Tese (Doutorado) - Universidade de São Paulo, São Paulo

RIBEIRO, A. H. P.; ANDRADE, D. F., et al. Competência em Marketing e Performance: os Construtos, as Dimensões e suas Relações. EMA. Rio de Janeiro, 2006.

SOLOMON, M. O comportamento do consumidor: comprando, possuindo e sendo. Porto Alegre: Bookman, 2002.

STRAUSS, L. R. Folha on line: Faculdade vê na mídia solução contra crise, 31/08/2003. Disponível em <http://www1.folha.uol.com.br/folha/dinheiro/ ult91u72772.shtml>. Acesso em 09 de setembro de 2008.

VENKATRAMAN, N.; RAMANUJAM, V. Measurement of Business Performance in Strategy Research: A Comparison of Approaches. Academy of Management Review. v. 11, n. 4, p. 801-814, 1986.

WEBSTER, F. Top Management's Concerns about Marketing: Issues for the 1980's. Journal of Marketing, v. 45, 1981. 